JURNAL KEBIDANAN

Vol 6, No 4, Oktober 2020 : 462-469

\title{
JUS BIT MERAH (Beta vulgaris L.) BERMANFAAT MENINGKATKAN KADAR HEMOGLOBIN IBU HAMIL DENGAN ANEMIA
}

\author{
Dewita $^{1}$, Henniwati² \\ 1,2Program Studi D III Kebidanan Langsa Politeknik Kesehatan Kemenkes Aceh \\ 1email: witadewita1980@gmail.com \\ 2email: henniwati976@yahoo.com
}

\begin{abstract}
Background: Pregnant women are at risk of anemia caused by various things. In general, the cause of anemia in pregnant women is iron deficiency which triggers folate deficiency. According to WHO, the incidence of anemia around $42 \%$ occurs in pregnant women with middle to lower economic conditions. The impact of anemia on the mother can experience postpartum hemorrhage caused by uterine atony and premature birth. While the effects of anemia on infants can result in babies born with low birth weight, fetal death in the uterus, asphyxia and intra-uterine growth restriction (IUGR). Beetroot (Beta vulgaris $L$ ) contains vitamins $A, B$, and $C$, and contains iron, calcium and phosphorus which can stimulate the circulatory system.

Purpose: to determine the provision of red beet juice to the increase in $\mathrm{Hb}$ levels in pregnant women with anemia in the working area of Langsa City Health Center.

Methods: This type of research is quasi experimental, pretest and posttest one model design. This study consisted of 2 groups, namely the group giving Fe tablets as a control group, the group giving beetroot juice as the intervention group. Duration of treatment for 14 days. Each group was observed and checked for hemoglobin levels before and after the intervention. The analysis used to determine the effect of red beet juice and Fe tablets on the increase in hemoglobin levels of anemic pregnant women using the paired T-test (Sig 0.000).

Results: Beetroot treatment group, mean hemoglobin at pretest was $10.033 \mathrm{gr} / \mathrm{dl}$ and posttest was 11.507 with a difference of 1.474, meaning that there was an increase in hemoglobin levels after being given red beet juice treatment of $1.474 \mathrm{gr} / \mathrm{dl}$. The test used is the paired t-test with the Sig. $0.000(<0.05)$, meaning that there is an effect of giving red beet juice with hemoglobin of pregnant women with anemia. In the control group, the mean hemoglobin at pretest was $10.027 \mathrm{~g} / \mathrm{dl}$ and $10.747 \mathrm{~g} / \mathrm{dl}$ in the posttest with a difference of 0.72 , meaning an increase in hemoglobin levels was 0.72. The paired t-test results showed the Sig. $0.000(<0.05)$, which means that there is an effect of giving Fe tablets with hemoglobin in pregnant women with anemia.

Conclusion: There is an effect of Red Beet Juice and Fe Tablets to increase $\mathrm{Hb}$ levels in pregnant women with anemia

Suggestion For pregnant women, they can choose beetroot as an alternative to handling cases of anemia during pregnancy. Meanwhile, for health workers to carry out socialization about red beets is very beneficial for public health
\end{abstract}

Keywords: Beetroot Juice, Fe Tablets, Hb Levels, Pregnancy Anemia.

\section{ABSTRAK}

Latar Belakang : Ibu hamil beresiko terjadi anemia yang disebabkan oleh berbagai hal. Secara umum penyebab ibu hamil anemia karena defisiensi besi yang memicu terjadi defisiensi folat. Menurut WHO angka kejadian anemia sekitar $42 \%$ terjadi pada ibu hamil dengan kondisi ekonomi kalangan menengah kebawah. Dampak anemia pada ibu dapat mengalami perdarahan postpartum yang disebabkan karena atonia uteri dan kelahiran prematur. Sedangkan efek anemia pada bayi dapat mengakibatkan bayi lahir dengan BBLR, Kematian janin dalam Rahim, asfiksia dan intra uterin growth restriction (IUGR). Bit merah (Beta vulgaris $L$ ) mengandung vitamin $A, B$, dan $C$, serta mengandung zat besi, kalsium dan fosfor yang dapat merangsang sistem peredaran darah.

Tujuan : untuk mengetahui pemberian jus Bit merah terhadapa peningkatan kadar $\mathrm{Hb}$ pada ibu hamil dengan anemia di wilayah kerja Puskesmas Kota Langsa.

Metode : Jenis penelitian quasi experimental, pretest and posttest one model design. Penelitian ini terdiri dari 2 kelompok yaitu kelompok pemberian tablet Fe sebagai kelompok kontrol, kelompok pemberian Jus Bit merah 
sebagai kelompok intervensi. Lamanya Perlakuan yang dilakukan selama 14 hari. Setiap kelompok diobservasi dan dilakukan pemeriksaan kadar hemoglobin sebelum dan setelah diberikan intervensi. Analisis yang digunakan untuk mengetahui pengaruh pemberian Jus Bit merah dan tablet Fe terhadap peningkatan kadar hemoglobin ibu hamil anemia dengan menggunakan uji paired T-test (nilai Sig 0.000).

Hasil : kelompok perlakuan Bit merah, rerata hemoglobin pada saat pretest sebesar 10,033 gr/dl dan posttest sebesar 11,507 dengan selisih 1,474, artinya terjadi kenaikan kadar hemoglobin setelah diberikan perlakuan jus Bit merah sebesar 1,474 gr/dl. Uji yang digunakan adalah paired t-test dengan nilai Sig. 0,000 $<$ $0,05)$, artinya terdapat pengaruh pemberian jus bit merah dengan hemoglobin ibu hamil dengan anemia. pada kelompok kontrol dengan pemberian tablet Fe rerata hemoglobin saat pretest sebesar 10,027 gr/dl dan posttest $10,747 \mathrm{gr} / \mathrm{dl}$ dengan selisih 0,72, berarti terjadi kenaikan kadar hemoglobin sebesar 0,72. Hasil uji paired t-test didapatkan hasil nilai Sig. 0,000 $(<0,05)$, artinya terdapat pengaruh pemberian tablet Fe dengan hemoglobin ibu hamil dengan anemia.

Kesimpulan : ada pengaruh pemberian Jus Bit Merah dan Tablet Fe terhadap peningkatan kadar $\mathrm{Hb}$ pada ibu hamil dengan Anemia

Saran . Bagi ibu hamil agar dapat memilih Bit merah sebagai salah satu altrenatif terhadap penanganan kasus anemia selama kehamilan. Sedangkan bagi petugas kesehatan agar melaksanakan sosialisasi tentang buah Bit merah sangat bermanfaat terhadap kesehatan masyarakat

Kata Kunci : Jus Bit merah, Tablet Fe, Kadar kadar Hb, Anemia Kehamilan

\section{PENDAHULUAN}

Anemia merupakan masalah terbesar terjadi di negara maju maupun berkembang yang dapat mempengaruhi kesehatan masyarakat sebesar 1,62 milyar orang dan juga termasuk kesehatan ibu dan anak. Anemia dapat terserang pada semua kelompok umur, namun ibu hamil dan anak-anak lebih rentan terkena anemia. Secara global anemia pada ibu hamil disebabkan oleh defisiensi zat besi (Obai, Odongo, \& Wanyama, 2016).

Anemia adalah suatu keadaan dimana kadar eritrosit dan atau hemoglobin $(\mathrm{Hb})$ yang beredar dalam tubuh tidak dapat memenuhi fungsinya untuk menyediakan oksigen. Dapat dikatakan pula bahwa terjadi penurunan kadar $\mathrm{Hb}$, hematokrit atau hitung eritrosit dibawah normal. Seorang perempuan hamil didiagnosis mengalami anemia apabila memiliki kadar hemoglobin dibawah $11 \mathrm{gr} / \mathrm{dl}$ (WHO Global Database on Anaemia, 2008). Untuk mencegah terjadi anemia ibu harus mengkonsumsi tablet besi dan folat secara rutin dan dilanjutkan sampai 3 minggu postpartum (WHO, 2016).

Kasus defisiensi besi pada ibu hamil merupakan masalah didunia dengan angka kejadian hampir $75 \%$ terjadi pada semua jenis anemia kehamilan. Prevalensi anemia dalam kehamilan sangat bervariasi karena perbedaan kondisi sosial, gaya hidup dan perilaku mencari kesehatan lintas budaya yang berbeda. Anemia dapat mempengaruhi wanita hamil di seluruh dunia (prevalensi global dalam kehamilan diperkirakan sekitar 41,8\%) dengan tingkat prevalensi berkisar antara 35 hingga $60 \%$ untuk Afrika, Asia dan Amerika Latin dan dilaporkan $<20 \%$ di negara industri. Perkiraan prevalensi anemia terendah adalah $5,7 \%$ di AS dan tertinggi $75 \%$ di Gambia dan $65-75 \%$ di India (Carlo et al, 2015).

World Health Organization (WHO), memperkirakan sebanyak 1,62 milyar penduduk dunia mengalami anemia dan 56,4 juta dari penderita anemia tersebut merupakan perempuan hamil. WHO memperkirakan jumlah perempuan hamil yang menderita anemia di Asia Tenggara sebanyak 18,1 juta. Asia Tenggara memiliki prevalensi tertinggi dibandingkan dengan Afrika, Amerika, Eropa, Asia Pasifik dan Mediterania Timur (WHO Global Database on Anaemia, 2008). Anemia berhubungan dengan defisiensi besi yang berdampak pada angka kesakitan dan kematian meningkat (Nora, 2018).

Kasus ibu hamil dengan anemia Indonesia meningkat sebesar $11,8 \%$ dalam 5 tahun terakhir yaitu tahun 2018 ibu hamil dengan anemia sebesar $48,9 \%$ diantaranya jumlah ibu hamil anemia paling tinggi pada usia 15-24 tahun sebesar $84,6 \%$, usia 25-34 tahun sebesar 33,7 5, usia 35-44 tahun sebesar 33,6 \%, dan usia 45-54 tahun sebesar $24 \%$ (Balitbangkes, 2018). Sedangkan kasus anemia pada ibu hamil di Kota langsa sebesar 534 kasus dari 4.024 ibu hamil (Dinas Kesehatan Kota Langsa, 2019).

Anemia dapat disebabkan oleh berbagai hal. Penyebab utama anemia pada kehamilan adalah defisiensi besi kemudian diikuti oleh defisiensi folat. WHO memperkirakan angka kejadian anemia sekitar $42 \%$ terjadi pada ibu hamil dengan kondisi ekonomi menengah kebawah (Kemenkes, 2018). Kekurangan zat besi, dan asam folat dapat menyebabkan anemia pada ibu hamil. Dampak anemia pada ibu hamil yaitu 
gangguan pertumbuhan pada sel tubuh maupun sel otak, mengakibatkan kurangnya oksigen yang ditransfer ke sel tubuh maupun ke otak. Anemia pada ibu dapat mengalami perdarahan postpartum yang disebabkan karena atonia uteri (Rimawati et al., 2018) dan lahir prematur. Selain itu anemia pada ibu hamil dapat mengakibatkan bayi lahir dengan BBLR, Kematian janin dalam Rahim, asfiksia dan intra uterin growth restriction (IUGR) (Stephen et al., 2018).

Bit merah (Beta Vulgaris $L$ ) adalah jenis umbiumbian yang sering digunakan sebagai pewarna alami untuk berbagai jenis makanan, kaya akan folat yang ampuh untuk mencegah penyakit jantung dan anemia. Buah bit yang dikenal dengan akar bit mapun bit merah ini merupakan salah satu jenis tanaman dari kelompok Amaranthaceae dan memiliki nama latin Beta Vulgaris. Bit merah mengandung serat, baik yang mudah larut maupun sulit larut, serat yang tidak mudah larut membantu memperlancar kerja usus, sedangkan serat yang mudah larut kadar gula dan kolesterol darah tetap stabil (Suryandari, 2015).

Bit merah (Beta vulgaris $L$ ), yang memiliki senyawa aktif betalain. Senyawa Betalain merupakan pigmen mengandung nitrogen yang dapat larut air. Bit merah terdapat senyawa aktif betalain (Clifford, et al, 2015). Senyawa betalain disebut juga dengan asam betalamat dan turunannya betacyanin dan betaxanthin (Mereddy, et al, 2016). Betalain juga umum digunakan sebagai pewarna alami untuk pengolahan pangan. Betalain memiliki sifat sebagai antioksidan, sehingga mampu melindungi komponen tubuh dari gangguan stres oksidatif (Ninfali \& Angelino, 2013). Pemberian Jus Bit merah yang diberikan pada remaja putri dengan anemia di SMA negeri Chenai Tamilnadu, dilakukan pretest dan posttest pemeriksaan kadar hemoglobin. Jus Bit merah selama 20 hari pada pagi hari menunjukkan peningkatan kadar hemoglobin meningkat dibandingkan dengan kelompok kontrol (Priya, 2013).

Bit merah (Beta vulgaris $L$ ) mengandung vitamin $A, B$, dan $C$ dengan kadar air yang tinggi. Bit merah juga mengandung zat besi, kalsium dan fosfor yang bekerja dengan merangsang sistem peredaran darah dan membantu membangun sel darah merah karena kandunga asam folat dan B12 dalam Bit Merah adalah kunci penting dalam metabolisme seluler dan dibutuhkan dalam perkembangan normal eritrosit. Bit juga membersihkan dan memperkuat darah sehingga darah dapat membawa zat gizi ke seluruh tubuh sehingga jumlah sel darah merah tidak akan berkurang (Putri et al., 2016).

Hasil survey dilakukan pada pada 10 orang ibu hamil, 8 orang ibu hamil mengeluh minum tablet fe dapat membuat mual muntah sehingga ibu hamil tidak mau mengkonsumsinya lagi dan secara tidak langsung kasus anemia belum dapat diatasi. Tujuan penelitian ini adalah untuk mengetahui pengaruh pemberian Jus Bit Merah dan Tablet Fe terhadap peningkatan kadar $\mathrm{Hb}$ pada ibu hamil dengan Anemia di wilayah kerja puskesmas Kota Langsa. Oleh sebab itu, penelitian tentang ini dianggap perlu dikaji lagi apakah ada pengaruh pemberian jus Bit merah dan tablet Fe terhadap peningkatan kadar hemoglobin pada ibu hamil anemia di wilayah kerja Puskesmas langsa Kota.

Penelitian ini berbeda dengan penelitian Suryandari, (2015), dimana penelitian ini memberi perlakuan pemberian jus bit merah saja tanpa ditambah dengan tablet $\mathrm{Fe}$, diberikan pada ibu hamil trimester dua, dosis jus bit merah yang diberikan 250 $\mathrm{ml}$ perhari selama 14 hari. Cara mengatasi anemia adalah dengan pemberian terapi tablet antianemia $(\mathrm{Fe})$, yang mana ibu hamil harus mengkonsumsi tablet $\mathrm{Fe}$ sebanyak 90 tablet selama masa kehamilan. Berdasarkan hasil survey yang peneliti lakukan ibu hamil banyak mengeluh tablet fe dapat merangsang mual muntah sehingga tidak mau mengkonsumsinya lagi dan secara tidak langsung kasus anemia belum dapat diatasi. Penulis ingin melihat pengaruh pemberian Jus Bit Merah dan tablet Fe terhadap peningkatan kadar Hemoglobin pada ibu hamil dengan anemia di Wilayah Kerja Puskesmas Kota Langsa

\section{METODELOGI PENELITIAN}

Rancangan penelitian yang digunakan adalah quasi experiment dengan pretest and posttest design, untuk mengetahui perbedaan kadar hemoglobin pada ibu hamil anemia yang diberikan Jus Bit merah dan tablet Fe di Wilayah Kerja Puskesmas Kota Langsa. Lokasi penelitian Puskesmas Kota Langsa, dengan Jumlah sampel 30 orang. Kelompok perlakuan ada 2 yaitu kelompok intervensi yang berikan Jus Bit merah $250 \mathrm{ml}$ satu kali/24 jam pada pagi hari selama 14 hari, sedangkan kelompok perlakuan diberikan tablet Fe satu hari sekali selama 14 hari. Kriteria inklusi adalah lbu hamil dengan anemia ringan dan sedang, Ibu hamil trimester dua dan tiga, lbu hamil anemia yang tidak mengkonsumsi suplemen atau obat untuk penyakit apapun. Sedangkan kriteria eksklusi adalah ibu hamil dengan anemia berat, riwayat alergi makanan, dan ibu hamil dengan penyakit gastrointestinal, talasemia, tukak lambung.

Instrumen penelitian yaitu kuesioner berupa daftar observasi dengan cara melakukan wawancara untuk memgamati tanda gejala anemia dengan memberi skoring. Jumlah skor maksimum 20, 
dengan interpretasi skor anemia yaitu anemia ringan jumlah skor 1-7, anemia sedang skor 8-14 dan anmeia berat 15-20. Alat yang digunakan untuk mengukur kadar hemoglobin yaitu digital Easy Touch Gchb. Pengukuran kadar hemoglobin dilakukan sebanyak 2 kali yaitu pada saat sebelum perlakuan (pretest) dan setelah perlakuan (posttest). Penelitian ini sudah mendapatkan persetujuan etik dari tim komisi etik Poltekkes Aceh dengan No. 1. B. $02.03 / 8177 / 2019$. Analisa data menggunakan data univariat dan bivariat kemudian dianalis dengan paired t-test.

\section{HASIL PENELITIAN}

Berdasarkan penelitian yang dilakukan pada tanggal 19 Agustus s/d 03 September 2019 di Wilayah Kerja Puskesmas Langsa Kota Kota Langsa dengan 30 responden ibu hamil yang mengalami anemia, didapatkan hasil:

\section{Karakteristik ibu}

Berdasarkan tabel diatas, diketahui bahwa pada kelompok perlakuan dari 15 responden mayoritas usia ibu 20-35 tahun sebanyak 13 orang $(86,7 \%)$, mayoritas ibu dengan jumlah anak $2-4$ (multigravida) sebanyak 7 orang $(46,7 \%)$ dan mayoritas ibu tidak bekerja sebanyak 10 orang $(66,7 \%)$. Pada kelompok kontrol dari 15 responden, mayoritas usia ibu 20-35 tahun sebanyak 11 orang $(73,3 \%)$, mayoritas jumlah anak ibu 2-4 (multigravida) sebanyak 8 orang $(53,3 \%)$ dan mayoritas ibu tidak bekerja sebanyak 8 orang $(53,3 \%)$.

Tabel 1.

Distribusi Frekuensi Karakteristik Ibu Berdasarkan Usia, Paritas dan Pekerjaan

\begin{tabular}{lcccc}
\hline \multirow{2}{*}{ Karakteristik Ibu } & \multicolumn{2}{c}{ K. Perlakuan } & \multicolumn{2}{c}{ K. Kontrol } \\
\cline { 2 - 5 } & $\mathbf{F}$ & $\%$ & $\mathbf{F}$ & $\%$ \\
\hline Usia & 13 & 86,7 & 11 & 73,3 \\
20-35 Tahun & 2 & 13,3 & 4 & 26,7 \\
>35 Tahun & & & & \\
Paritas & 6 & 40 & 5 & 33,3 \\
Primigravida & 7 & 46,7 & 8 & 53,3 \\
Multigravida & 2 & 13,3 & 2 & 13,4 \\
Gande Multigravida & & & & \\
Pekerjaan & 5 & 33,3 & 7 & 46,7 \\
Bekerja & 10 & 66,7 & 8 & 53,3 \\
Tidak Bekerja & & & & \\
\hline
\end{tabular}

Frekuensi Anemia

Kelompok Kontrol (Fe)

Tabel 2.

Distribusi Frekuensi Anemia Pretest dan Posttes Pada Kelompok Kontrol (Fe) Pada Ibu Hamil

\begin{tabular}{ccccc}
\hline \multirow{2}{*}{ Anemia } & \multicolumn{4}{c}{ Kelompok Buah Bit } \\
\cline { 2 - 5 } & \multicolumn{2}{c}{ Pretest } & \multicolumn{2}{c}{ Posttest } \\
\cline { 2 - 5 } & $\mathbf{F}$ & $\%$ & $\mathbf{F}$ & $\%$ \\
\hline Tidak Anemia & 0 & 0 & 10 & 66,7 \\
Anemia Ringan & 15 & 100 & 5 & 33,3 \\
\hline
\end{tabular}

Berdasarkan tabel diatas diketahui bahwa kelompok kontrol dengan pemberian $\mathrm{Fe}$, pada saat pretest didapatkan seluruh ibu hamil mengalami anemia ringan sebanyak 15 orang $(100 \%)$ dan setelah pemberian (posttest) mayoritas ibu mengalami anemia ringan 8 orang $(53,3 \%)$ dan ibu tidak mengalami anemia sebanyak 7 orang $(46,7 \%)$.
Kelompok Perlakuan ( Bit merah)

Tabel 3.

Distribusi Frekuensi Anemia Pretest dan Posttest Pada Kelompok Bit Merah Ibu Hamil

\begin{tabular}{ccccc}
\hline Anemia & \multicolumn{3}{c}{ Kelompok Kontrol (Fe) } \\
\cline { 2 - 5 } & \multicolumn{2}{c}{ Pretest } & \multicolumn{2}{c}{ Posttest } \\
\cline { 2 - 5 } & $\mathbf{F}$ & $\%$ & $\mathbf{F}$ & $\%$ \\
\hline Tidak Anemia & 0 & 0 & 7 & 46,7 \\
Anemia Ringan & 15 & 100 & 8 & 53,3 \\
\hline
\end{tabular}

Berdasarkan tabel diatas diketahui bahwa kelompok buah Bit merah, pada saat pretest didapatkan seluruh ibu hamil mengalami anemia ringan sebanyak 15 orang (100\%) dan setelah pemberian (posttest) mayoritas ibu mengalami tidak anemia sebanyak 10 orang $(66,7 \%)$ dan ibu mengalami anemia ringan sebanyak 5 orang $(33,3 \%)$.

Uji Pairet t-test 
Pengujian ini dilakukan untuk mengetahui Pengaruh Buah Bit Terhadap Kadar Hemoglobin pada ibu Hamil Anemia di Puskesmas Langsa Kota dengan menggunakan pengujian Uji Paired T-Test. Hasil dapat dilihat pada tabel dibawah ini :

Tabel 4.

Hasil uji Paired T-Tes Buah Bit Merah Terhadap Kadar Hemoglobin

\begin{tabular}{lccc}
\hline \multicolumn{1}{c}{ Kelompok } & Rerata & Selisih Rerata & Sig. \\
\hline Kelompok Kontrol (Tablet Fe) & 10,027 & & \\
$\begin{array}{l}\text { Pretest } \\
\text { Posttest }\end{array}$ & 10,747 & 0,72 & 0,000 \\
$\begin{array}{l}\text { Kelompok Perlakuan ( Bit merah) } \\
\text { Pretest }\end{array}$ & 10,033 & & \\
Posttest & 11,507 & 1,474 & 0,000 \\
\hline
\end{tabular}

Berdasarkan tabel diatas menunjukan bahwa, pada kelompok kontrol dengan pemberian tablet $\mathrm{Fe}$ rerata hemoglobin saat pretest sebesar 10,027 gr/dl dan posttest 10,747 gr/dl dengan selisih 0,72, yang berarti terjadi kenaikan kadar hemoglobin sebesar 0,72 . Setelah di uji menggunkan uji paired t-test didapatkan hasil nilai Sig. $0,000 \quad(<0,05)$ yaitu terdapat pengaruh pemberian tablet $\mathrm{Fe}$ dengan Hemoglobin ibu anemia.
Pada kelompok perlakuan dengan pemberian Bit merah, rerata Hemoglobin pada saat pretest sebesar 10,033 $\mathrm{gr} / \mathrm{dl}$ dan posttest sebesar 11,507 dengan selisih 1,474, yang berarti terjadi kenaikan kadar Hemoglobin setelah diberikan perlakuan Bit merah sebesar 1,474 gr/dl. Setelah di uji menggunakan uji paired t-test didapatkan hasil nilai Sig. $0,000 \quad(<0,05)$ yaitu terdapat pengaruh pemberian buah Bit merah dengan Hemoglobin ibu anemia.

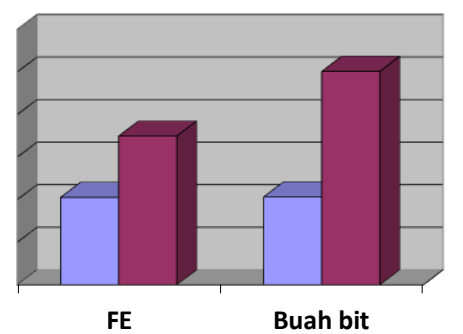

$\square$ Pretest $\square$ Posttest

Gambar 1.

Rerata kadar hemoglobin pretest dan posttest pemberian perlakuan pada kelompok Kontrol (Fe) dan perlakuan (Bit merah)

Pada gambar diatas diketahui bahwa rerata sebelum dan setelah perlakukan didapat, pada kelompok kontrol dengan pemberian tablet Fe rerata kadar Hemoglobin sebelum perlakuan seberar $10,027 \mathrm{gr} / \mathrm{dl}$ dan setelah diberi perlakuan menjadi sebesar 10,747 gr/dl, yang artinya terjadi peningkatan kadar Hemoglobin sebesar 0,72 gr/dl.

Pada kelompok perlakuan rerata sebelum dan setelah pemberian Bit merah didapat, pada sebelum perlakuan rerata sebesar 10,033 dan setelah diberi perlakuan sebesar 11,507 gr/dl, yang artinya terjadi peningkatan kadar Hemoglobin setelah diberikan buah Bit merah sebesar 1,474 $\mathrm{gr} / \mathrm{dl}$.

\section{PEMBAHASAN}

Pengaruh pemberian Jus Bit merah (Beta vulgaris $L$ ) terhadap peningkatan kadar Hemoglobin pada ibu hamil dengan anemia.

Dari hasil penelitian bahwa ibu hamil anemia yang diberi perlakuan jus Bit merah terbukti mampu meningkatkan kadar hemoglobin di wilayah kerja Puskesmas Langsa Kota.Pada. Data yang didapat menunjukkan bahwa kelompok perlakuan yang diberi jus Bit merah, rerata Hemoglobin pada saat pretest sebesar 10,033 $\mathrm{gr} / \mathrm{dl}$ dan posttest sebesar 11,507 dengan selisih 1,474, yang berarti terjadi kenaikan kadar Hemoglobin setelah diberikan perlakuan buah Bit merah sebesar 1,474 gr/dl. Setelah di uji menggunakan uji paired t-test didapatkan hasil nilai Sig. 0,000 $(<0,05)$ yaitu 
terdapat pengaruh pemberian jus Bit merah dengan Hemoglobin ibu anemia.

Penelitian ini sejalan dengan Suryandari, (2015), bahwa pemberian jus Bit merah ditambah dengan tablet Fe selama 1 minggu pada ibu hamil terbukti signifikan dapat meningkatkan kadar Hemoglobin lebih tinggi dibandingkan tablet Fe saja. Penelitian ini didukung oleh Manjulavathi, (2016), dimana pemberian jus Bit merah yang diberikan pada remaja yang telah menarche dengan anemia defisiensi besi di Institut pelatihan guru Sree balaji Chennai, terbukti secara signifikan dapat meningkatkan kadar Hemoglobin dengan nilai $\mathrm{P}<$ 0,001 .

Kandungan nutrisi didalam Bit merah per 100 $g$ adalah sebagai berikut: vitamin $\mathrm{A} 20 \mathrm{IU}$, tiamin 0,02 $\mathrm{mg}$, riboflavin $0,05 \mathrm{mg}$, niasin $0,4 \mathrm{mg}$, vitamin C 10 $\mathrm{mg}$, kalsium $27 \mathrm{mg}$, zat besi $1,0 \mathrm{mg}$, fosfor $43 \mathrm{mg}$, serat $87,4 \mathrm{~g}$, lemak $1 \mathrm{~g}$, karbohidrat 9,6 g, protein 1,6 $\mathrm{g}$, kalori 42 kkal per $100 \mathrm{~g}$. Selain iru daun Bit merah tidak kalah dengan buah bit merah yang sama-sama memiliki nilai gizi, namun jarang dikonsumsi daunnya (Babarykin et al., 2019).

Selain itu pemberian ekstrak etanol Bit merah dengan dosis 250 dan $500 \mathrm{mg} / \mathrm{hari} / \mathrm{kgBB}$ terbukti mampu meningkatkan ekspresi VEGF dan ketebalan endometrium pada tikus Rattus norvegicus yang dipapar asap rokok, karena asap rokok dapat menurunkan estrogen sehingga merusak follikel ovarium dan menghambat proliferasi endometrium, yang mungkin terjadi infertilitas (Hanum et al, 2018).

Konsumsi Bit merah dapat terjadi Beeturia, yangmana urin menjadi merah dan kadang-kadan feses berwarna agak gelap. Farmakokinetik kadar betalain dalam Bit merah dalam urin manusia sehat yang dikonsumsi secara sukarela, terdapat kadar betalain dalam urin yang konsumsi jus Bit merah setelah 24 jam sekita 60-369 mg kadar betalain dari hasil minum jus Bit merah sebanyak 300-500 ml. Betasianin lebih cepat diserap oleh usus dan mulai tampak pada urin setelah 2 jam konsumsi Bit merah, namun hanya sekitar $0,28 \%$ yang tercerna dalam tubuh sisa nya terekskresi dalam urin (Neelwarne, 2012). Sampai saat ini belum diketahui uji toksisitas pemberian Bit merah pada manusia, penulis hanya memberi perlakuan pada ibu hamil dengan anemia dengan Jus Bit senyak $250 \mathrm{ml}$, ini sesuai dengan dosis penelitan sebelumnya oleh Lotfi et al, (2018), pada atlet wanita yang diberi bit merah 200 ditambah air $50 \mathrm{ml}$ yang terbukti mencegah anemia.

\footnotetext{
Pengaruh pemberian tablet $\mathrm{Fe}$ terhadap peningkatan kadar Hemoglobin pada ibu hamil dengan anemia.
}

Dari hasil penelitian pemberian tablet fe pada ibu hamil dengan anemia selama 14 hari terbukti mampu meningkatkan kadar hemoglobin pada ibu hamil dengan anemia di wilayah kerja Puskesmas langsa Kota. Data yang didapat menunjukan bahwa, pada kelompok kontrol dengan pemberian tablet $\mathrm{Fe}$ rerata Hemoglobin saat pretest sebesar 10,027 gr/dl dan posttest 10,747 gr/dl dengan selisih 0,72, yang berarti terjadi kenaikan kadar Hemoglobin sebesar 0,72 . Setelah di uji menggunakan uji paired t-test didapatkan hasil nilai Sig. $0,000 \quad(<0,05)$ yaitu terdapat pengaruh pemberian tablet $\mathrm{Fe}$ dengan Hemoglobin ibu anemia.

Penelitian ini sejalan dengan penelitian Ratih, (2017), hasil penelitian yang berjudul pengaruh pemberian tablet zat besi $(\mathrm{Fe})$ terhadap peningkatan kadar Hemoglobin pada ibu hamil yang anemia bahwa, kadar Hemoglobin ibu hamil yang anemia sebelum mengkonsumsi tablet zat besi ( $\mathrm{Fe}$ ) 8,81 $\mathrm{g} / \mathrm{dL}$. Kadar Hemoglobin ibu hamil yang anemia sesudah mengkonsumsi tablet zat besi ( $\mathrm{Fe}$ ) 12,58 $\mathrm{gr} / \mathrm{dL}$. Artinya ada pengaruh peningkatan kadar hemoglobin pada ibu hamil yang anemia sebelum dan sesudah pemberian tablet zat besi $(\mathrm{Fe})$ dengan nilai p.value $<0,05$ yaitu $P$ value 0,001 .

Hasil penelitian didukung oleh Nurhayati, dkk, (2015), yang mana ada pengaruh pemberian tablet Fe selama 12 hari terhadap peningkatan kadar Hemoglobin pada ibu hamil trimester III dengan anemia. Tablet besi ( $\mathrm{Fe}$ ) sangat efektif untuk menggantikan zat besi yang diperlukan oleh tubuh agar kadar Hemoglobin meningkat. Sebaiknya konsumsi tablet besi bersamaan dengan vitamin $\mathrm{C}$ agar dapat menyerap zat besi dalam usus. Efek samping dari tablet besi biasanya, mual, kembung dan sembelit (Colman \& Pavord, 2017).

Efek anemia dalam kehamilan yaitu: anemia ringan tidak memeliki efek terhadap kehamilan dan persalinan kecuali simpanan besi dalam tubuh rendah sehingga memperparah anemia. Anemia sedang disebabkan lemah, lelah, kurangnya energi dan melakukan pekerjaan berat. Sedangkan anemia berat dengan sering dikaitkan dengan kemiskinan. Tanda gejala anemia berat yaitu palpitasi, takikardi, sesak napas, peningkatan curah jantung dan gagal jantung yang mengakibatkan terjadi persalinan prematur, pre eklamsi, dan sepsis. Sedangkan bayi dapat lahir prematur dan dapat mengakibatkan asfiksia serta kematian perinatal (Sharma \& Shankar, 2010).

Berdasarkan hasil penelitian pada kedua kelompok masih ditemukan kejadian anemia pada ibu hamil setelah pemberian perlakuan pada kedua kelompok tersebut, dimana kelompok perlakuan Bit merah masih terdapat kelompok kontrol dengan 
pemberian $\mathrm{Fe}$, pada saat pretest didapatkan seluruh ibu hamil mengalami anemia ringan sebanyak 15 orang $(100 \%)$ dan setelah pemberian (posttest) mayoritas ibu mengalami anemia ringan 8 orang $(53,3 \%)$ dan ibu tidak mengalami anemia sebanyak 7 orang $(46,7 \%)$. Sedangkan kelompok buah Bit merah, pada saat pretest didapatkan seluruh ibu hamil mengalami anemia ringan sebanyak 15 orang $(100 \%)$ dan setelah pemberian (posttest) mayoritas ibu mengalami tidak anemia sebanyak 10 orang $(66,7 \%)$ dan ibu mengalami anemia ringan sebanyak 5 orang $(33,3 \%)$.

Penulis berasumsi, kemungkinan terjadi karena pengaruh paritas ibu hamil dimana terdapat ibu hamil dengan multigravida sebesar $46,7 \%$ pada kelompok pemberian Bit merah dan ibu hamil dengan multigravida sebesar $53,3 \%$ pada kelompok tablet Fe. Dimana paritas menunjukkan ada hubungan sebab akibat kejadian anemia, kerena semakin sering seorang ibu melahirkan maka akan beresiko kehilangan darah yang berefek terhadap penurunan kadar Hemoglobin (Ristica, 2013). Maka dari diperlukan tambahan nutrisi yang mengandung asam folat dan zat besi pada ibu hamil anemia dan mungkin membutuhkan waktu yang panjang dalam meningkat kadar $\mathrm{Hb}$ normal pada ibu hamil.

\section{KESIMPULAN}

Berdasarkan hasil penelitian secara umum, ada pengaruh pemberian Jus Bit Merah dan Tablet $\mathrm{Fe}$ terhadap peningkatan kadar $\mathrm{Hb}$ pada ibu hamil dengan Anemia di wilayah kerja puskesmas Kota Langsa.

\section{SARAN}

Saran bagi peneliti selanjutnya agar dapat menggunakan waktu pemberian intervensi yang lebih panjang kepada ibu hamil dengan anemia sehingga dapat melihat pengaruh sangat signifikan terhadap kenaikan kadar hemoglobin. Bagi ibu hamil agar dapat memilih Bit merah sebagai salah satu altrenatif terhadap penanganan kasus anemia selama kehamilan. Sedangkan bagi petugas kesehatan agar melaksanakan sosialisasi tentang buah Bit merah sangat bermanfaat terhadap kesehatan masyarakat.

\section{DAFTAR PUSTAKA}

Babarykin, D., Smirnova, G., Pundinsh, I., Vasiljeva, S., Krumina, G., \& Agejchenko, V. (2019). Red Beet (\&lt;i\&gt;Beta vulgaris\&lt;/i\&gt;) Impact on Human Health. Journal of Biosciences and Medicines, 07(03), 61-79. https://doi.org/10.4236/jbm.2019.73007

Balitbangkes. (2018). Hasil Utama Riskesdas Tentang Prevalensi Diabetes Mellitus di Indonesia 2018. https://doi.org/1 Desember 2013

Carlo, G., Renzo, D., \& Giardina, I. (2015). 10.2217@Whe.15.35. Womens Health.

Clifford, T., Howatson, G., West, D. J., \& Stevenson, E. J. (2015). The potential benefits of red beetroot supplementation in health and disease. Nutrients, 7(4), 2801-2822. https://doi.org/10.3390/nu7042801

Colman, K., \& Pavord, S. (2017). Iron deficiency anaemia in pregnancy Information for patients. Retrieved from https://www.ouh.nhs.uk/patientguide/leaflets/files/14412Panaemia.pdf

Dinas Kesehatan Kota Langsa. (2019). Laporan Kasus tahun 2018.

Hanum Zulfa., Dewita Dewita, Handono Kusworini, Nurdiana, S. E. (2018). Pengaruh Ekstrak Bit Merah ( Beta vulgaris L .) Terhadap VEGF, dan Ketebalan Endometrium Pada Tikus ( Rattus norvegicus ) Dipapar Asap Rokok Public Health Faculty Universitas Muslim Indonesia Address: Email: Phone: Article history: Received 19 June. 1(3), 133-140.

Lotfi, M., Azizi, M., Tahmasbi, W., \& Bashiri, P. (2018). The Effects of Consuming 6 Weeks of Beetroot Juice (Beta vulgaris L.) on Hematological Parameters in Female Soccer Players. Journal of Kermanshah University of Medical Sciences, In Press(In Press). https://doi.org/10.5812/jkums.82300

Manjulavathi, G. (2016). A Study to Assess the Effectiveness of Beetroot Juice on $\mathrm{Hb}$ Level Among Middleage Women in Sree Balaji Teacher Training Institute, Chromepet . chennai .( Tn ). Indian Journal Of Research, 5(12), 53-55.

Masrizal. (2007). Studi Literatur Anemia Defisiensi Besi. Jurnal Kesehatan Masyarakat, 2: (1), II(1), 140-145.

Mereddy, R., Fanning, K., Chan, A., Sultanbawa, Y., \& Nirmal, N. (2016). Betalain rich functional extract with reduced salts and nitrate content from red beetroot (Beta vulgaris L.) using membrane separation technology. Food Chemistry, 215, 311-317. https://doi.org/10.1016/j.foodchem.2016.07.1 32

Neelwarne, B. (2012). Preface. In Red Beet Biotechnology: Food and Pharmaceutical Applications. https://doi.org/10.1007/978-14614-3458-0 
Ninfali, P., \& Angelino, D. (2013). Nutritional and functional potential of Beta vulgaris cicla and rubra. Fitoterapia, 89(1), 188-199. https://doi.org/10.1016/j.fitote.2013.06.004

Nora, M. A. (2018). Effect of red beetroot (Beta vulgaris L.) intake on the level of some hematological tests in a group of female volunteers. ISABB Journal of Food and Agricultural Sciences, 8(2), 10-17. https://doi.org/10.5897/isabb-jfas2017.0070

Nurhayati, N., Halimatusakdiah, P. K. A., \& Asniah, A. (2015). PENGARUH ASUPAN TABLET ZAT BESI (Fe) TERHADAP KADAR HAEMOGLOBIN (Hb) PADA IBU HAMIL DI PUSKESMAS KOPELMA DARUSSALAM TAHUN 2014. Idea Nursing Journal, 6(1), 7682.

Obai, G., Odongo, P., \& Wanyama, R. (2016). Prevalence of anaemia and associated risk factors among pregnant women attending antenatal care in Gulu and Hoima Regional Hospitals in Uganda: A cross sectional study. BMC Pregnancy and Childbirth, 16(1), 1-7. https://doi.org/10.1186/s12884-016-0865-4

Priya, N. G. (2013). Beet root juice on haemoglobin among adolescent girls. IOSR Journal of Nursing and Health Science, 2(1), 09-13. https://doi.org/10.9790/1959-0210913

Putri, M. C., Tjiptaningrum, A., Kedokteran, F., Lampung, U., Klinik, B. P., Kedokteran, F., \& Lampung, U. (2016). Efek Antianemia Buah Bit ( Beta vulgaris L . ) Antianemic Effect Of Beetroot ( Beta vulgaris L . ). Jurnal Majority, 5(4), 96-100.

Ratih, R. H. (2017). Pengaruh Pemberian Tablet Zat Besi (Fe) Terhadap Peningkatan Kadara Hemoglobin Pada Ibu Hamil Yang Anemia. Jomis (Journal Of Midwifery Science), 1(1), 30-34.

Rimawati, E., Kusumawati, E., Gamelia, E., Achadi Nugraheni, S., Kesehatan, F., Dian
Nuswantoro, U., ... Diponegoro, U. (2018). Intervensi Suplemen Makanan Untuk Meningkatkan Kadar Hemoglobin Pada Ibu Hamil Food Supplement Interventions for Increasing Hemoglobin Level on Pregnant Women. Jurnal IImu Kesehatan Masyarakat, 9(3), 161-170. https://doi.org/10.26553/jikm.2018.9.3.161170

Ristica, O. D. (2013). Faktor Risiko Kejadian Anemia pada Ibu Hamil Risk Factors Related to Anemia in Pregnant Women. Jurnal Kesehatan Komunitas, 2(2), 78-82.

Sharma, J. B., \& Shankar, M. (2010). Anemia in Pregnancy . PREVALENCE OF ANEMIA IN. Indian Journal of Medical Research, 23(4), 253-260.

Stephen, G., Mgongo, M., Hussein Hashim, T., Katanga, J., Stray-Pedersen, B., \& Msuya, S. E. (2018). Anaemia in Pregnancy: Prevalence, Risk Factors, and Adverse Perinatal Outcomes in Northern Tanzania. Anemia, 2018. https://doi.org/10.1155/2018/1846280

Suryandari, A. E. (2015). Jurnal Kebidanan DIBERI Fe DENGAN Fe DAN BUAH BIT DI WILAYAH KERJA Amaranthaceae dan memiliki nama latin zat besi sekitar hampir $7 \%$ serta asam folat. Jurnal K, VII(01), 36-47.

Susiloningtyas, I. (2012). PEMBERIAN ZAT BESI (Fe) DALAM KEHAMILAN Oleh: Is Susiloningtyas. Suhardjo, 2003, 50, 128.

WHO. (2016). Iron and folate supplementation, Intergrated Management of Pregnancy and Childbirth (IMPAC).

WHO Global Database on Anaemia. (2008). Worldwide prevalence of anaemia. World Health Organization. https://doi.org/10.1017/S1368980008002401 